Research, part of a Special Feature on Integrating Indigenous Ecological Knowledge and Science in Natural Resource Management: Perspectives from Australia

\title{
Australian Aboriginal Peoples' Seasonal Knowledge: a Potential Basis for Shared Understanding in Environmental Management
}

\author{
$\underline{\text { Suzanne M. Prober }}^{1}, \underline{\text { Michael H. O'Connor }}^{1}$, and Fiona J. Walsh $^{1}$
}

\begin{abstract}
Natural resource scientists and managers increasingly recognize traditional ecological knowledge (TEK) for its potential contribution to contemporary natural resource management (NRM) and, through this, to more resilient social-ecological systems. In practice, however, inadequate cross-cultural means to organize and communicate TEK can limit its effective inclusion in management decisions. Indigenous seasonal knowledge involving temporal knowledge of biota, landscapes, weather, seasonal cycles, and their links with culture and land uses is one type of TEK relevant to this issue. We reviewed the literature on Australian Aboriginal seasonal knowledge to characterize contemporary and potential applications to NRM. This knowledge was often documented through cross-cultural collaboration in the form of ecological calendars. Our analysis revealed a variety of basic and applied environmental information in Aboriginal seasonal descriptions and calendars that can contribute directly to NRM. Documented applications have been limited to date, but include fire management, inclusion as general material in NRM plans, and interpretative information about environments. Emerging applications include water management and climate change monitoring. Importantly, seasonal knowledge can also contribute indirectly to NRM outcomes by providing an organizing framework for the recovery, retention, and crosscultural communication of TEK and linking to its broader cultural and cosmological contexts. We conclude that by facilitating the combination of experiential with experimental knowledge and fostering complementarity of different knowledge systems, Aboriginal seasonal knowledge can increasingly contribute to more resilient social-ecological outcomes in NRM. Nevertheless, the seasonal framework should augment, rather than override, other approaches to cross-cultural NRM such as those with spatial and/or social-ecological emphasis.
\end{abstract}

Key Words: Australia; Indigenous calendars; Indigenous seasons; natural resource management; traditional ecological knowledge

\section{INTRODUCTION}

There has been increasing global interest in accounting for different knowledge frameworks in the sustainable management of natural resources (Borrini-Feyerabend et al. 2004, Walker et al. 2004, Bennett and Zurek 2006, Berkes et al. 2006). This includes interdisciplinary research to integrate different branches of Western science (e.g., the social and ecological sciences), but importantly, also involves counterbalancing Western viewpoints with the ecological knowledge of indigenous people (hereafter traditional ecological knowledge [TEK]; Gadgil et al. 1993). From the perspective of environmental management (hereafter natural resource management [NRM]), it is assumed that this will result in more resilient social-ecological systems through the incorporation of a broader information base, consideration of a wider diversity of culturally derived ideals, and elucidation of conflicts and synergies (Holling et al. 2002, Folke et al. 2003, Folke 2004, Walker et al. 2004).

Although it is widely recognized that inclusion of indigenous perspectives and knowledge is needed for more resilient and equitable NRM outcomes, many authors point to a lack of practical methods for achieving this inclusiveness (Usher 2000, Casimirri 2003, Bennett and Zurek 2006, Houde 2007). According to Usher (2000:185), part of this 
challenge involves a need for "attention to appropriate methods of organizing and presenting TEK (to nonindigenous people)" for environmental assessment and management. This is especially the case because traditional media of TEK are not readily communicated to outsiders. Knowledge is derived from experience and shared from person to person, encoded in language and artworks (oral, body, and diagrammatic), and not traditionally recorded in written form (Usher 2000, Hill et al. 2004, Hennessey et al. 2007). Further, not unlike specialist facets of Western science, different components of indigenous knowledge often have different owners or keepers, so that a complete body of knowledge is rarely held by any one individual (Usher 2000).

Indigenous seasonal knowledge, involving knowledge of the weather, seasonal cycles of plants and animals, and their links with indigenous culture and land uses, is one form of TEK potentially relevant to NRM (Simpson 1997, Folke et al. 2003, Clarke 2009). Traditionally, indigenous people relied on an intimate knowledge of seasonal patterns to secure an ongoing supply of food, medicines, and other resources. They interpreted the stars, weather, and other physical and biological indicators to predict biological events and signal when to pursue cultural activities (Clarke 2007). For example, in southeast Queensland, string-like processions of hairy caterpillars predicted the clustering of breeding mullet in the waterways (O'Connor 1997); in British Columbia, the call of the Swainson's thrush (Catharis (Hylocichla) ustulata Nuttal, 1840) indicated that salmonberries (Rubus spectabilis Pursh) would soon be ripe and ready to harvest (Lantz and Turner 2003). When collated over an annual cycle (or longer in variable environments), this type of information forms the basis of indigenous ecological calendars, also known as seasonal calendars (e.g., Fig. 1). These are mostly cross-cultural constructs that, in Australia, have been documented over the past century by anthropologists, ethnobiologists, and Aboriginal people for many different Aboriginal language groups (Clarke 2009). Superficially, they can be viewed as timetables that divide the year into seasons and describe expected conditions and resource availability. A more in-depth view recognizes that indigenous seasonal knowledge comprises organized artisanal knowledge gained through observation and adjustment over timeframes of thousands of years, often strongly linked with an ontology such as that shaped by the
"Dreaming" of Australian Aboriginal culture (or Jukurrpa in Western Desert languages; see Myers 1986, Nicholls 2006).

Indigenous ecological calendars differ significantly from the standardized Western or Gregorian calendar. The Gregorian calendar focuses on structural time (Aveni 1989), whereas indigenous concepts were typically built around ecological time (Aveni 1989, Harrison 2007). Although the Western calendar contains seasons and can incorporate place-specific seasonal characteristics, its contemporary use is predominantly as a fixed system of reference that positions us in time and deals particularly with social concerns (Aveni 1989). By contrast, concepts of ecological time that underpin indigenous seasonal knowledge emphasize cyclical processes and are embedded strongly in place and the ecology of that place (Usher 2000). As such, they are intimately linked with activities that drive NRM.

Several recent papers have examined indigenous seasonal knowledge from various perspectives. In a Canadian analysis, Lantz and Turner (2003) emphasized the phenological knowledge it includes; in an Australian study, Clarke (2009) highlighted its cultural and spiritual context. An increasing number of works examine the importance of indigenous knowledge for adaptation to climate change, typically focusing on knowledge regarding impacts, local response strategies, or weather forecasting capacity (e.g., Hennessey et al. 2007, Parry et al. 2007, Salick and Ross 2009, Turner and Clifton 2009, Green and Raygorodetsky 2010, Green et al. 2010). However, the value of indigenous ecological calendars and associated seasonal knowledge for informing NRM more widely has not been systematically assessed. Thus, we reviewed the literature on Australian Aboriginal (hereafter Aboriginal) ecological calendars and indicators to characterize their potential and contemporary application to NRM, and thereby, to evaluate how Aboriginal seasonal knowledge can contribute in practice to building social-ecological resilience as defined by Folke et al. (2003).

\section{METHODS}

We synthesized publicly available information from published articles, book chapters, reports, websites, media (including artworks and movies), leaflets, and manuscript collections. To help locate information, we undertook systematic searches of 
Fig. 1. A Warlpiri calendar from central Australia showing a representation of traditional seasonal knowledge framed by the 12-month Gregorian calendar. Redrawn from Hoogenraad and Robertson (1997) and used with permission.

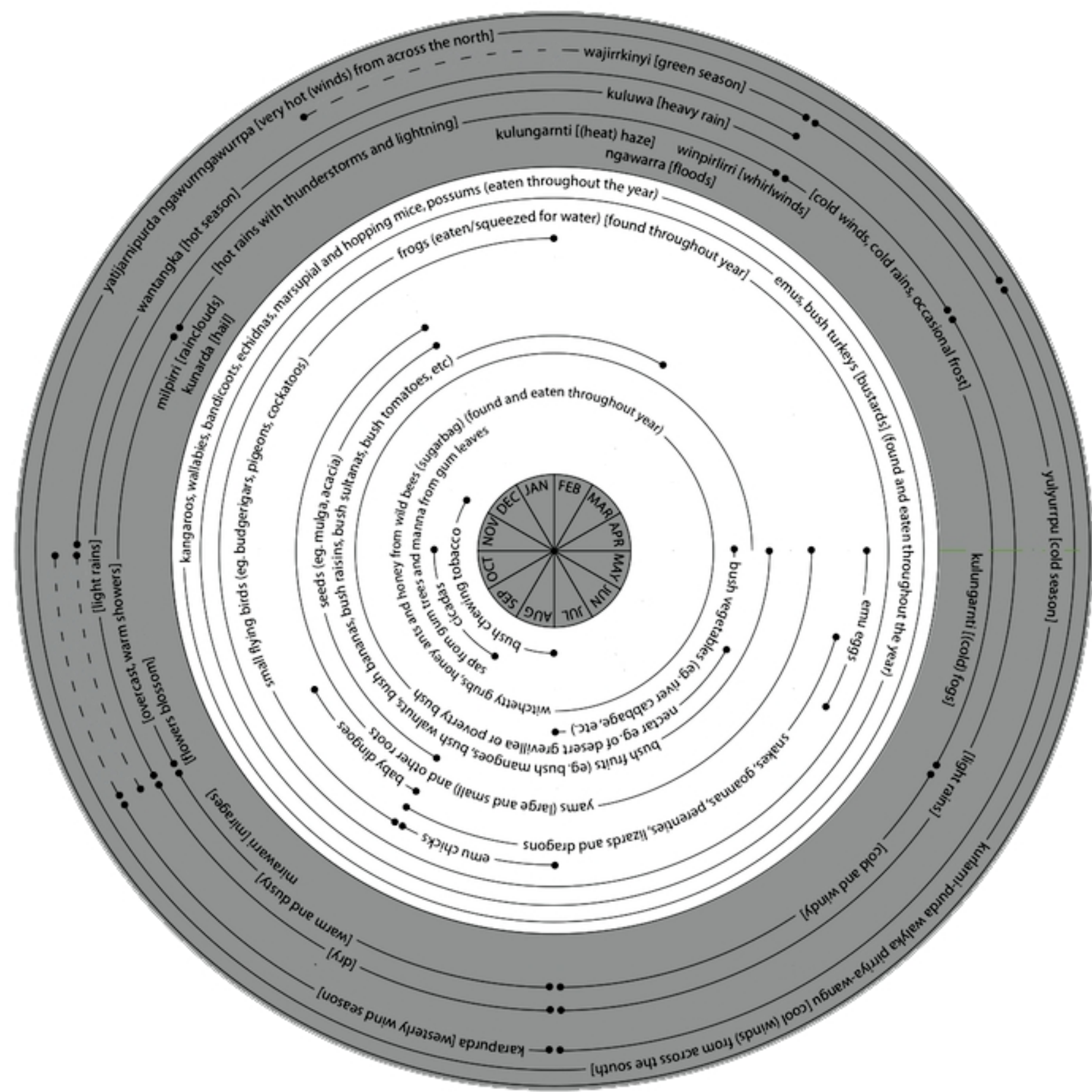


the terms: (Aboriginal OR indigenous) AND (season OR calendar OR indicator) on Google, Google Scholar, ISI Web of Knowledge, and the INFORMIT database (http://www.informit.com.au/ ). The latter incorporates the Australian Institute of Aboriginal and Torres Strait Islander Studies collection.

We structured our analysis of material pertaining to Aboriginal seasonal knowledge according to a simplification of the TEK classes identified by Usher (2000) and Houde (2007), as outlined in Table 1. First, we explored how seasonal knowledge can contribute directly to the NRM knowledge base by contributing basic knowledge of the environment (our TEK class 1), as well as knowledge of Aboriginal use and management of the environment (our TEK class 2; Table 1). Second, we analyzed how the seasonal framework can contribute indirectly to NRM as a knowledge framework reflecting and communicating broader Aboriginal knowledge systems (our TEK class 3; Table 1). Relevance to principles for building socialecological resilience developed by Folke et al. (2003), particularly with regard to living with change (evoking disturbance, expecting the unexpected), nurturing diversity through socialecological memory, and combining different knowledge types, was considered at each of these steps.

We took an Australia-wide perspective (excluding Torres Strait Islands) in our analysis, but recognize that Aboriginal socio-linguistic groups positioned their observations to precise places or wider habitats within their socio-linguistic region. We also acknowledge that Aboriginal groups conceptualized time in multiple, complex dimensions shaped by action, subject, and place (see Munn 1992), which we do not address. Because our analysis was limited to recorded documentation, knowledge encoded in other forms such as language and experience will have been missed. We have given Aboriginal words for plants, animals, and seasons where possible; associated language group names were determined from identifiers in the cited sources and standardized using the AUSTLANG database (http ://austlang.aiatsis.gov.au/). Scientific names are in accordance with the Council of Heads of Australasian Herbaria's Australian plant census ( http://www.chah.gov.au/apc) and the Australian Biological Resources Survey's faunal directory ( http://www.environment.gov.au/biodiversity/abrs/onlineresources/fauna/afd/index.html).

\section{RESULTS AND DISCUSSION}

Of the 350-750 Aboriginal language dialects in Australia, our search revealed at least one literature source of seasonal information for 86 dialects. For 10 of these, we found multiple sources with varying degrees of difference in seasonal information, which may represent dialectic variation or uneven ethnographic recording. Aspects of seasonal knowledge identified within the assembled sources ranged from minimal, e.g., one or more words for seasons or a single seasonal indicator, to richly documented descriptions arranged as an ecological calendar in tabular or circular form. These included artistic depictions, scientific identifications of plant and animal species, collections of seasonal indicators, and terms in the local Aboriginal language. In the more complex diagrammatic formats, Aboriginal seasons were usually crossreferenced to approximate Gregorian months (e.g., Hoogenraad and Robertson 1997; Fig. 1).

Seasonal knowledge was recorded from a historical perspective in most of the documents we surveyed, commonly for the purpose of preserving or communicating Aboriginal knowledge for its intrinsic value or future potential application, including NRM (e.g., Wightman 2003). Direct contemporary application of seasonal knowledge to cross-cultural NRM was evident only in a small subset of documents: 15 out of 86 language groups. However, a number of elements of Aboriginal seasonal knowledge with the potential to contribute more widely to NRM, and thus social-ecological resilience, were also evident. Our discussion considers both these contemporary and potential applications.

\section{Basic knowledge of the environment}

Basic knowledge of ecological systems includes description of the different components and processes associated with particular ecosystems, their interrelationships, and short- and long-term dynamics. This type of information can contribute to contemporary NRM by describing baseline conditions and establishing a basis from which to monitor, predict, and respond to change (Usher 2000, Folke et al. 2003, Houde 2007). The documents we surveyed portrayed a wide range of basic environmental knowledge elements, with an emphasis on links among physical phenomena such as astronomy, weather, and landscape, and biological phenomena such as plants and animals. 
Table 1. Adaptation of traditional ecological knowledge (TEK) classification systems as used to structure our review. Numbering refers to the class numbers used by the authors indicated and by us. Classes from Usher (2000), Houde (2007), and our classification are grouped together in rows to indicate their approximate alignment.

\begin{tabular}{|c|c|c|c|}
\hline $\begin{array}{l}\text { TEK class } \\
\text { (Usher 2000) }\end{array}$ & $\begin{array}{l}\text { TEK class } \\
\text { (Houde 2007) }\end{array}$ & $\begin{array}{l}\text { TEK class } \\
\text { (this review) }\end{array}$ & $\begin{array}{l}\text { Aboriginal seasonal knowledge } \\
\text { attributes discussed in this review }\end{array}$ \\
\hline
\end{tabular}

Direct application to natural resource management 1. Basic knowledge of the $\quad 1$. Factual observations
environment

2. Knowledge of Aboriginal use of the 2. Management systems environment in the present and past 3 . Past and current land uses

\author{
1. Basic knowledge of the - Abiotic (astronomical, weather, \\ environment landscape) \\ - Biotic (plant, animal) \\ - Links through indicators \\ 2. Knowledge of Aboriginal - Resource use \\ use and management of the - Fire management \\ environment \\ - Spatio-temporal variation in \\ hunting and gathering \\ - Responding to multi-year \\ variations in biotic and abiotic \\ environments
}

Indirect application to natural resource management
3. Values and ideals
4. Ethics and values
4. Knowledge systems
5. Culture and identity
6. Cosmology

- Not explicitly considered in this review

3. Knowledge frameworks
These included reference to at least 12 different astronomical indicators, including the "Emu" (dark dust clouds near the Southern Cross) and Pleiades (Seven Sisters) as the most commonly mentioned constellations. They were linked with broad seasonal shifts (Fig. 2; Walsh 1990, 2008, Andrews 2004, Norris and Norris 2009) and to particular biological events such as the whelping of dingo pups in the Western Desert (reappearance of Pleiades at dusk; Simpson 1997, Norris and Norris 2009) and the time that Emu lay their eggs in southeastern and southwestern Australia (position of the Emu constellation; Norris and Norris 2009, O'Connor and Prober 2010). A range of other astronomical indicators provide basic biological and weather knowledge (Clarke 2009, Norris and Norris 2009,
Green et al. 2010; Museum Victoria, Seven seasons of the Kulin people: http://museumvictoria.com.au/ forest/climate/kulin.html). For example, the appearance of the constellation Lyra in March signaled when Mallee fowl (Leipoa ocellata Gould, 1840), an iconic and declining bird of southern Australia, were about to build their nests; the disappearance of Lyra in October indicated when they were laying their eggs (Norris and Norris 2009). Similarly, in southern Victoria Gurrbora (koala, Phascolarctos cinereus Goldfuss, 1817) are recorded as beginning to mate at the time the star Arcturus is seen on the northwestern horizon soon after sunset (Museum Victoria, Seven seasons of the Kulin people: http://museumvictoria.com.au/forest/ climate/kulin.html; language group Woiwurrung). 
The sun and moon were rarely referred to in the calendars we surveyed, but it is well established that they played a role in Aboriginal daily life and mythology (Dodd and McKelson 2007, Clarke 2009). For example, the sun's east-west movement helped to reference the prevailing wind directions (Clarke 2009), and the Nyangumarta of northwestern Australia traditionally used moon and sun phases to distinguish time periods at relatively short temporal scales (months and days; Dodd and McKelson 2007). In a more predictive sense, observations of the moon by elderly Yaraldi men of western Victoria indicated whether roaring equinoctial gales (krungkun) would soon recede (Berndt et al. 1993). We found no evidence for application of these temporal concepts to contemporary NRM.

In most documents, seasonal weather conditions were described in general terms translated as hot, cold, wet, or other named periods. More detailed weather characteristics, e.g., frost, wind direction, or cloud patterns, were also reported and sometimes related directly to biological events. For example, the dramatic "morning glory" clouds of the Gulf of Carpentaria were associated with the arrival of fruit bats, Rainbow Parrot (presumably Trichoglossus haematodus rubritorquis Linnaeus, 1771), and Torres Strait Pigeon (Ducula bicolor Scopoli, 1786; Bradley et al. 1989 in Simpson 1997, Baker 1993); cold southeast winds in northwestern Australia indicated to the Nyangumarta when the threadfin (Polydactylus sp.) and bluenose salmon (Eleutheronema tetradactylum Shaw, 1804) were running (Dodd and McKelson 2007).

Basic biological information about plants transmitted through ecological calendars most commonly included their regional presence and the seasons of their flowering, fruit ripening, tuber maturity, greening, and/or senescence. More specific phenological and spatial information was also encoded. For example, flower and nectar production in Banksia dentata L.f. in the northern Queensland ranges was specifically indicated by the position of the constellation Orion (Clarke 2009). Occasionally, more complex references provided other basic information on plant ecology, such as river dispersal of fruits of the red wabuwabu (an unspecified native cherry), recorded in the KukuYalanji calendar (Anderson 1985).

Weather, plant flowering events, and other seasonal indicators often pointed to the condition, breeding status, or arrival of terrestrial or marine fauna. Examples of seasonal faunal activity indicated include mass movement of fish up rivers (Anderson 1985, Hill et al. 2004), egg laying by crocodiles (Bureau of Meteorology 2009a), breeding of bundjil (Wedge-tailed Eagle, Aquila audax Latham, 1802; Museum Victoria, Seven seasons of the Kulin people: http://museumvictoria.com.au/forest/climate/ kulin.html; language group Woiwurrung), and the descending of Brush Turkey (Alectura lathami J. E. Gray, 1831) from ranges to feed (Hill et al. 2004). A multitude of more detailed behavioral information about fauna has also been recorded, such as turtles feeding on blue marine jellyfish (Baker 1993), chirruping of yurata-yurata (tetigonid crickets; Walsh 2008; language group Martu Wangka; Fig. 2), seed-eating birds moving south (Foreign Affairs and Trade 1997), or juwogban (Rain Bird, Eudynamys scolopaceus Linnaeus, 1758) "calling out" when buda (Vitex glabrata R. Br.) fruit is ripe (Bureau of Meteorology 2009a; language group Wardaman).

Although the calendars we surveyed contained abundant baseline seasonal knowledge, we found few documented examples of direct application of this knowledge to enhancing environmental management and resilience. Walsh (2008), however, suggested that seasonal information would be useful for refining the timing of biological surveys (see also Dowsley 2009 for an Inuit example), and other authors have noted its applicability to environmental impact assessments (Usher 2000). A more common use was the inclusion of an ecological calendar within the background section of NRM plans, providing an alternative ecological context or "social-ecological memory" (Folke et al. 2003) to increase the diversity of knowledge informing management decisions (e.g., Green 1988, Moore 2007, Smyth 2007, unpublished manuscript Ballardong NRM Working Group http://www.wheatbeltnrm.org.au/resources/ ballardong noongar budjar.pdf.

An emerging application of baseline Aboriginal seasonal knowledge is its relevance to climate change research and adaptation (Green et al. 2010, O'Connor and Prober 2010). Phenological records, dating back hundreds of years (e.g., over 1300 years of Japanese cherry blossom flowering records; Cleland et al. 2007), provided some of the earliest indications of climate change in the northern hemisphere (e.g., Lantz and Turner 2003, Parmesan 2006, Cleland et al. 2007, Lawrence 2009). In Australia, such written records are rarely available; 
Fig. 2. Representation of a Martu (northwestern Australia) ecological calendar that demonstrates interannual variation by showing a series of years. The calendar indicates greater predictability in physical than biological parameters. Jakulyukulyu is the Pleiades. Reproduced from Walsh (2008); language group Martu Wangka.

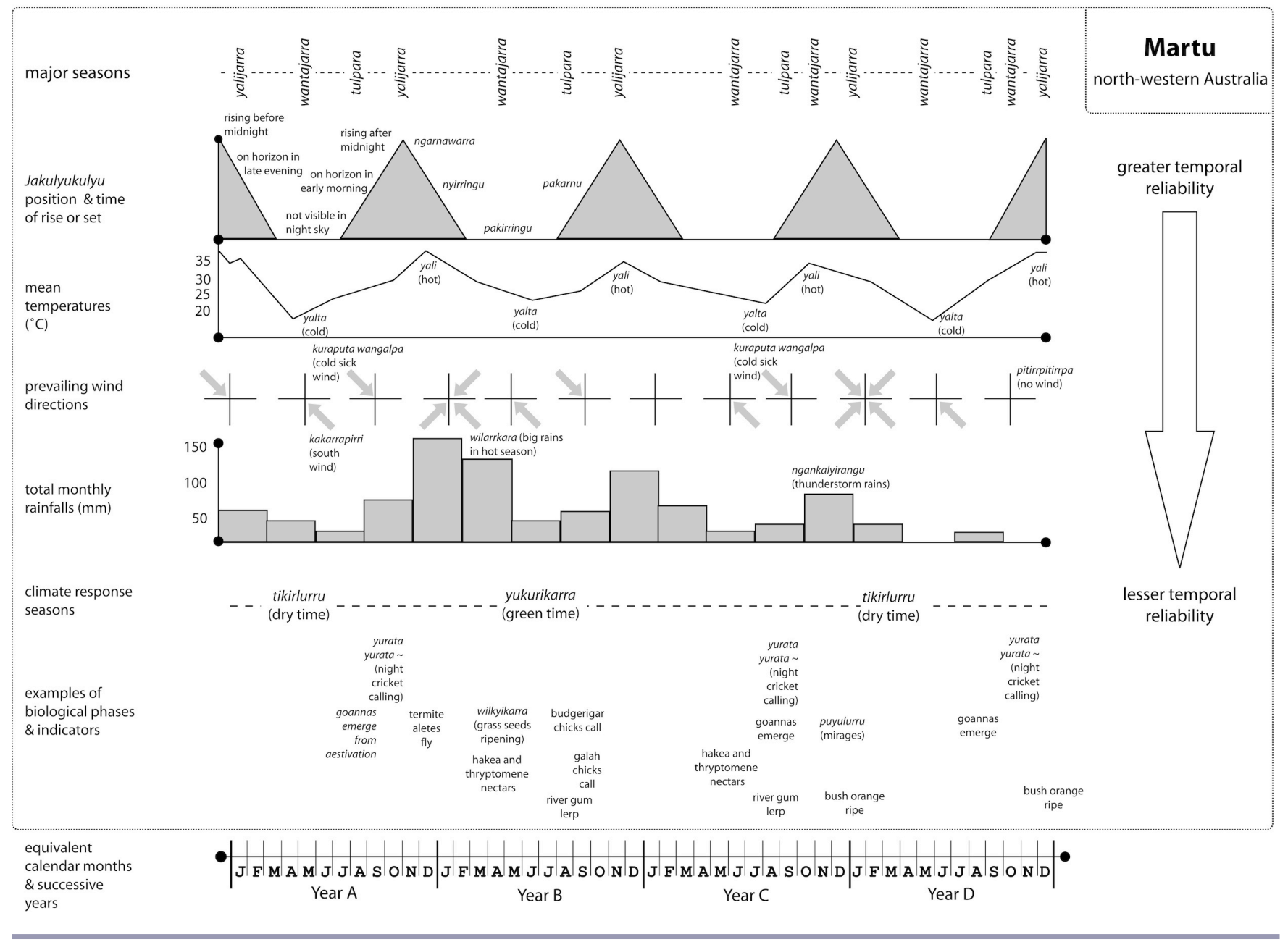

however, basic ecological knowledge inherent in long-standing Aboriginal seasonal indicators could provide an alternative. In particular, once-reliable seasonal indicators could become uncoupled in an altered climate, especially where climateindependent astronomical features indicate climatedependent biological events. Aboriginal seasonal indicators have not yet been widely applied to climate adaptation in Australia, but O'Connor and Prober (2010) recently documented a seasonal calendar for the Ngadju people in southwestern Australia toward this goal. Internationally, seasonal knowledge is also increasingly related to climate change (e.g., Orlove et al. 2000, Parry et al. 2007, Salick and Ross 2009, Turner and Clifton 2009). In northern Australia, it has been used to infer implications of climate change for human health (e.g., Cheng et al. 2008).

\section{Knowledge of Aboriginal use and management of the environment}

In addition to offering baseline environmental data, Aboriginal seasonal knowledge reflects traditional Aboriginal land and sea use and management 
(Usher 2000, Houde 2007; Table 1). Aboriginal management regimes typically aimed to maintain the abundance and diversity of food and other resources within the environment and fulfilled goals such as cleaning (burning) the country to make lands accessible (Russell-Smith et al. 1997, Walsh 2008). Given that local biota have evolved under Aboriginal management regimes over thousands of years, emulating or learning from these regimes should contribute to viable resource use, biodiversity conservation, and resilience of natural ecosystems in a contemporary context (e.g., Humphries 2007).

Knowledge regarding traditional management was the most common type of Aboriginal seasonal knowledge directly applied to contemporary NRM in the documents we surveyed. The most frequent application was to fire management in ecosystems of northern Australia (Lewis 1989, Lucas et al. 1997, Russell-Smith et al. 1997, Hill and Baird 2003, Bowman et al. 2004, Walsh et al. 2004), relevant to the concept of evoking disturbance as one of a sequence of practices that generate resilience (Folke et al. 2003). In these cases, calendar and seasonal information contributed to management assessments in conjunction with other types of Aboriginal fire knowledge, including spatially based, speciesbased, or ecosystem-based information. For example, the Kimberley Fire Management project documented an ecological calendar, a history line, and a land map with the Ngarinyin people as a basis to address concerns regarding the consequences of intensified fire regimes (Walsh et al. 2004). Aboriginal seasonal knowledge has also been applied to management of fresh water through similar mixed approaches, especially in northern Australia (e.g., Yu 2000, Jackson and O'Leary 2006, Woodward 2009).

Indigenous management associated with traditional resource use around the world has typically been regulated by customary rules and prescriptions that indicate the seasonal timing, frequency, intensity, and long-term patterning of usage (Anderson 2005), with the underlying role of sustaining a resilient and diverse resource base (Folke et al. 2003). Aboriginal prescriptions can be relevant to current harvest practices in Australia, including small-scale commercial harvest of wild bush foods and medicines such as kakadu plum (Terminalia ferdinandiana Exell), desert raisin (Solanum centrale J. M. Black), Acacia spp., and animal species (Gorman et al. 2006, Walsh and Douglas
2009), as well as broader commercial or recreational harvest of native species, especially marine foods.

Ecological calendars typically informed the seasonal component of these prescriptions by providing indicators of expected or suitable times for harvest, e.g., freshwater mussel "nice and fat" (Kuku-Yalanji in northeastern Queensland; Hill et al. 2004), or by highlighting vulnerable stages of life history (Gadgil et al. 1993). For example, yellow flowers of the mountain shrub bum gar indicated to Yugambeh people of southeastern Queensland that local cod species were out of bounds for fishing because it was their breeding time (O'Connor 1997). Additionally, ecological calendars provide an overview of the diversity of species traditionally used and may describe or imply other measures taken to maintain a sustainable resource. For example, seasonal descriptions from northern Queensland (Birkin et al. 1988; language group Winduwinda) noted that Uningan people were careful to ensure ongoing food supplies by replanting seed tubers of plants such as 'aanj (arrowroot, Tacca leontopetaloides [L.] Kuntze).

Seasonal knowledge also contributes to spatiotemporal approaches to sustainable resource use such as rotation of traditional grazing by herders in Africa and rotation of hunting and fishing grounds by Amerindians (Gadgil et al. 1993). In the Australian seasonal literature, we found few references to planned rotational harvests, but Birkin et al. (1988) emphasized how the Uningan moved to new locations before they seriously depleted a resource to maintain the long-term productivity of an area. Another spatio-temporal application involved the Wiradjuri of northeastern Victoria, who burned selected areas of the plains during weeitt, the season matching the western autumn (Kneebone 1993). As well as encouraging fresh grass for the following spring, this may have forced animals into the foothills, ensuring a food supply near winter campsites (Kneebone 1993).

Application of seasonal knowledge to contemporary resource harvesting was only occasionally explicit in the Australian documents we surveyed. One example noted that even in the 2000s, fishermen used the flowering of the Coast tea-tree (Leptospermum laevigatum [Gaertn.] F. Muell.) to mark the entry of snapper into Port Phillip Bay in Victoria (see seasonal calendars for the Melbourne area, compiled by B. Gott: http://home.vicnet.net.au/ herring/seasons.htm). The Balkanu Cape York 
Development Corporation (2004) emphasized the value of seasonal knowledge for application to contemporary management issues such as fish spawning closures. At a more general level, Smyth (2007) included Aboriginal seasonal knowledge in a review of Aboriginal use of the northwest sea country, toward development of the North West Marine Bioregional Plan.

While we have highlighted basic and applied elements of Aboriginal seasonal knowledge of potential value to NRM, we emphasize that the information content of recorded calendars was highly variable and often cursory (as noted also by Hoogenraad and Robertson 1997). For example, the number of distinct seasonal indicators we extracted from each calendar varied from zero to eleven. It was often difficult to determine the scientific names of plants and animals, and in many cases, groups of events were listed within a season without clarification of their sequence or importance as indicators. This variability partly reflects the different purposes for documenting these calendars. With an increasing shift from historical or educational goals toward the practical application of TEK, it is likely that more detailed ecological information could be incorporated into the calendar framework. For example, when we emphasized to Ngadju people of southwestern Australia the potential value of astronomical indicators for indicating effects of climate change, they shared astronomical information sufficiently specific for application to long-term monitoring; e.g., female jula (Emu, Dromaius novaehollandiae, 1790) begin laying eggs when the Seven Sisters are in the northwestern sky just after sundown (O'Connor and Prober 2010). We acknowledge, however, that traditional astronomical and other seasonal knowledge can be culturally sensitive; attempts to apply TEK to broader environmental management should identify and respect such sensitivities.

Further, the validity of information recorded in ecological calendars becomes increasingly important if it is to be applied to NRM; greater collaboration with Aboriginal knowledge holders to ensure accurate documentation is warranted. In our field experience, there is preliminary evidence that the seasonal ecological knowledge of Aboriginal groups, even in the Western Desert, has been severely fragmented, lost, or displaced by Western temporal constructs. For example, we observed Aboriginal school children who first named spring, summer, autumn, and winter, rather than local seasonal periods. These changes both constrain the direct application of local knowledge to NRM and underscore the urgency of TEK intergenerational transfer, recording, and repatriation.

Finally, while usually documented with a focus on annual cycles, seasonal knowledge is also relevant to longer-term cycles and interannual variability. This is especially the case in arid regions, where rainfall variability is the major driver of biological productivity (Morton et al. 2011) and substantially influenced customary resource use and activity (Latz 1995, Hoogenraad and Robertson 1997). Walsh (2008) emphasizes that circular calendars can be misleading because of these strong temporal variations and suggests their use in conjunction with longer-term linear calendars (e.g., Fig. 2). Decadal and longer-term seasonal information is typically poorly recorded (but see Museum Victoria, Seven seasons of the Kulin people: http://museumvictoria. com.au/forest/climate/kulin.html), and its broader inclusion in records of seasonal knowledge would be valuable for enhancing our capacity to live with change and uncertainty (Folke et al. 2003).

\section{Ecological calendars as knowledge frameworks}

Houde (2007) stresses that current approaches to involving indigenous people in contemporary NRM too often equate TEK with "a collection of data about the environment" and fail to acknowledge "the value system and cosmological context within which this traditional knowledge was generated." We argue that as well as providing such data, Aboriginal seasonal constructs offer a tool to organize this information and highlight these broader cultural and cosmological contexts, in turn, potentially facilitating a more holistic understanding and application of TEK in NRM.

First, through their temporal structure, calendars offer a framework to organize and communicate TEK within and across cultures. In the early stages of co-management, reconstruction of ecological calendars is a useful focus for facilitating knowledge collation and documentation within Aboriginal communities (e.g., Walsh and Mitchell 2002). For example, Woodward (2009) compiled an ecological calendar as a first step in a project on water management in the Northern Territory to record knowledge in an integrated framework and contribute to the local community by facilitating transfer of their knowledge from generation to 
generation. Similarly, Hoogenraad and Robertson (1997) describe the use of ecological calendars in central Australian schools to help young Aboriginal people value the traditional knowledge that they may otherwise not learn. We identified similar goals in documents from 19 other language groups. Notwithstanding, Hoogenraad and Robertson (1997) caution that the effectiveness of ecological calendars in contributing to knowledge transfer has not been tested.

For cross-cultural knowledge dissemination, Aboriginal ecological calendars and descriptions increasingly inform natural resource management through inclusion or consideration in management plans (see above), and the wider non-Aboriginal community through tourist information materials such as on-site interpretative boards, books, and brochures (e.g., Natural Resources, Environment, the Arts, and Sport http://www.brambuk.com.au/ga riwerdsixseasons.htm), and Aboriginal artworks (e. g., Foreign Affairs and Trade 1997; Aboriginal Art Online, http://www.aboriginalartonline.com/regions/ topend.php). Ecological calendars can thus contribute directly to NRM through their role in management planning and ecotourism while also raising community-wide awareness and acceptance of the role of TEK in land and sea management.

Second, beyond their role in organizing biological knowledge, ecological calendars can capture direct links among the seasonal cycles and the ecological, cultural, and spiritual aspects of traditional life (Lantz and Turner 2003, Clarke 2009; F. Walsh, V. P. Dobson, and J. Douglas, unpublished manuscript). For example, for the Brambuk of western Victoria, the appearance of the Emu constellation in the Milky Way Galaxy marked the spring abundance of birds' eggs and other foods, indicating the time to hold large gatherings to trade, seek marriage partners, settle legal conflicts, and hold corroborees (Bureau of Meteorology 2009b). Similarly, prolific flowering of tea-trees (Leptospermum spp.) on the Yorke Peninsula in southern Australia indicated the arrival of large numbers of fish, prompting Narangga people to plan initiation ceremonies during periods of abundant food supply (Clarke 2007). In turn, these links formed part of a belief system that underpinned daily life, evident in seasonal knowledge through perceptions about control of the weather or resources. For example, the constellation Pleiades was not only widely recognized across arid Australia as an indicator of the cold season (rising in the May dawn sky) or the hot season (rising at dusk in September), but was associated with female Ancestors who were considered to control the weather (Clarke 2009). Similarly, for the Karajarri of northwestern Australia, the rain birds kitirr (Fork-tailed Swift, Apus pacifus Latham, 1802) and wiyurr (Barn Swallow, Hirundo rustica Linnaeus, 1758) were seen not only to indicate the imminent occurrence of rain, but to "pull in the rain" (Yu 2000; language group Karajarri). An ecological calendar that encapsulates some of these stories and linkages is one potential means to interconnect the cultural and cosmological context of TEK.

Third, well-documented Aboriginal ecological calendars can be viewed as integrated, albeit simplistic, representations of indigenous NRM that offer some steps toward elucidating advantages of indigenous over Western NRM models (Usher 2000, Houde 2007; Table 1). In particular, links with Aboriginal customary livelihoods, culture, and spirituality help to emphasize the holistic nature of Aboriginal NRM, developed over thousands of years of adaptive management within a worldview that stresses respect for natural resources (Gadgil et al. 1993, Aikenhead and Ogawa 2007). This contrasts with NRM models built on Western science that traditionally focus on reductionist explanations and are accompanied by a worldview that sees humans as separate from and above the natural world (Gadgil et al. 1993, Aikenhead and Ogawa 2007). Reductionism has helped in manipulating and understanding simpler systems, but is less effective for managing complex socialecological systems (Folke et al. 2003, Gadgil et al. 1993). Emerging Western models of NRM such as those that incorporate concepts of sustainable development (Sayer and Campbell 2004, International Union for Conservation of Nature 2006) or social-ecological resilience (Folke et al. 2003, Walker et al. 2004) show greater similarity with holistic attributes of indigenous NRM through their attempts to integrate the social, economic, and environmental domains. As these Western models are still in their early development, learning from long-established indigenous NRM may help to embed these concepts.

As a final note, we emphasize that while our discussion has focused on seasonal frameworks, we do not imply that these should override other potential frameworks for fostering complementarity of different knowledge systems in NRM (Folke et al. 2003). Aboriginal livelihoods will always be 
strongly connected to land and resource tenure, which in turn are linked intrinsically with environmental knowledge of country through the agency of mythology. This includes paths or "songlines" travelled by ancestral beings (Baker 1993); many songlines encode environmental knowledge (e.g., Newsome 1980). Spatial approaches such as land maps are thus likely to be equally important for helping to convey TEK in its broader context. Social-ecological relationships to land and resource species as mediated through kinship networks represent another conceptual construct by which Aboriginal people organized their ecological knowledge (Warnayaka Art Centre and Glowczewski 2000).

\section{CONCLUSIONS}

We have argued that Aboriginal seasonal knowledge offers specific data relevant to NRM and provides a temporal framework for expressing Aboriginal resource management in its broader context. These attributes engender greater socialecological resilience in NRM because they facilitate Aboriginal knowledge recovery, retention, transfer, and application; connect with the cultural and cosmological context of TEK; and emphasize the holistic nature of Aboriginal NRM practice. However, seasonal frameworks should augment, rather than override, other approaches, such as those with a spatial emphasis, in fostering complementarity of knowledge systems in NRM.

We found that seasonal knowledge is not yet well embedded in NRM and recommend investigation of how its applications might be improved. Currently, there is a shortage of geographically focused case studies that document seasonal knowledge in sufficient detail to inform NRM. More targeted collection of seasonal information toward both TEK documentation and NRM outcomes, including climate change detection, monitoring, and adaptation, could contribute to improved application. Development of alternative graphic representations, beyond circular calendars and consistent with Aboriginal conceptual constructs for encoding knowledge, would also be valuable. In particular, increasing emphasis on long-term cycles and interannual variability could be particularly informative for achieving resilient social-ecological outcomes.
Responses to this article can be read online at: http://www.ecologyandsociety.org/vol16/iss 2/art12/ responses/

\section{Acknowledgments:}

This work was facilitated by James Butler and supported by the United Nations University. Fiona Walsh's development of Figure 2 was funded by the University of Western Australia, the Australian Institute of Aboriginal and Torres Strait Islander Studies, and the Desert Knowledge Cooperative Research Centre. We thank Tony Grice and Marcus Finn for comments on the manuscript.

\section{LITERATURE CITED}

Aikenhead, G. S., and M. Ogawa. 2007. Indigenous knowledge and science revisited. Cultural Studies of Science Education 2(3):539-620.

Anderson, J. C. 1985. The political and economic basis of Kuku-Yalanji social history. Dissertation. University of Queensland, Brisbane, Australia.

Anderson, M. K. 2005. Tending the wild: Native American knowledge and the management of California's natural resources. University of California Press, Berkeley, California, USA.

Andrews, M. 2004. The seven sisters of the Pleiades: stories from around the world. Spinifex Press, Melbourne, Australia.

Aveni, A. F. 1989. Empires of time: calendars, clocks, and cultures. Basic Books, New York, New York, USA.

Baker, R. 1993. Traditional Aboriginal land use in the Borroloola region. Pages 126-143 in N. M. Williams and G. Baines, editors. Traditional ecological knowledge: wisdom for sustainable development. Collection of papers from the Traditional Ecological Knowledge workshop. Centre for Resource and Environmental Studies, Australian National University, Canberra, Australia.

Balkanu Cape York Development Corporation. 2004. Living on saltwater country: Cape York Peninsula Sea Country management, needs and 
issues. Consultation report. National Oceans Office, Hobart, Australia. [online] URL: http://www.enviro nment.gov.au/coasts/mbp/publications/north/pubs/losccapeyork.pdf.

Bennett, E. M., and M. Zurek. 2006. Integrating epistemologies through scenarios. Pages 275-293 in W. Reid, F. Berkes, T. Wilbanks, and D. Capistrano, editors. Bridging scales and epistemologies: linking local knowledge and global science in environmental assessments. Island Press, Washington, D.C., USA.

Berkes, F., W. V. Reid, T. J. Wilbanks, and D. Capistrano. 2006. Conclusions. Bridging scales and knowldege systems. Pages 315-331 in W. Reid, F. Berkes, T. Wilbanks, and D. Capistrano, editors. Bridging scales and epistemologies: linking local knowledge and global science in environmental assessments. Island Press, Washington, D.C., USA.

Berndt, R. M., C. H. Berndt, and J. E. Stanton. 1993. A world that was: the Yaraldi of the Murray River and the lakes, South Australia. University of British Columbia Press, Vancouver, Canada.

Birkin, R., Z. Boxer, J. George, D. Donoghue, J. Hall, E. Hall, I. Hall, A. Mark, G. Motton, and E. York. 1988. Aborigines and their environment: life during the seasons. Pages 6-17 in G. Wharton, editor. Uningan guide: a handbook to the Uningan Bicentennial Nature and Recreation Reserve. Weipa Bicentennial Community Committee and the Priority Country Area Program-Northern Region, Cairns, Weipa, Australia.

Borrini-Feyerabend, G., A. Kothari, and G. Oviedo. 2004. Indigenous and local communities and protected areas: towards equity and enhanced conservation. IUCN, Gland, Switzerland, and Cambridge, UK. [online] URL: http://www.plateau perspectives.org/pubs/Indigineous\%20peoples.pdf

Bowman, D. M. J. S., A. Walsh, and L. D. Prior. 2004. Landscape analysis of Aboriginal fire management in Central Arnhem Land, north Australia. Journal of Biogeography 31(2):207-223.

Bureau of Meteorology. 2009a. Indigenous weather knowledge. Wardaman seasonal calendar. Bureau of Meteorology, Melbourne, Australia. [online] URL: http://www.bom.gov.au/iwk.
Bureau of Meteorology. 2009b. Aboriginal weather knowledge. Brambuk seasonal calendar. Bureau of Meteorology, Melbourne, Australia. [online] URL: http://www.bom.gov.au/iwk.

Casimirri, G. 2003. Problems with integrating traditional ecological knowledge into contemporary resource management. Pages 199-200 in Proceedings of the XII World Forestry Congress: Area A - Forests for people (Quebec City, 2003). CD-ROM. Food and Agriculture Organization, Quebec City, Canada. [online] URL: http://www.fao.org/DOCREP/ ARTICLE/WFC/XII/0887-A3.HTM.

Cheng, A. C., S. P. Jacups, L. Ward, and B. J. Currie. 2008. Melioidosis and Aboriginal seasons in northern Australia. Transactions of the Royal Society of Tropical Medicine and Hygiene 102(S1): S26-S29.

Clarke, P. A. 2007. Aboriginal people and their plants. Rosenberg Publishing, Dural Delivery Centre, New South Wales, Australia.

Clarke, P. A. 2009. Australian Aboriginal ethnometeorology and seasonal calendars. History and Anthropology 20(2):79-106.

Cleland, E. E., I. Chuine, A. Menzel, H. A. Mooney, and M. D. Schwartz. 2007. Shifting plant phenology in response to global change. Trends in Ecology and Evolution 22(7):357-365.

Dodd, T., and K. McKelson. 2007. Nganarna Nyangumarta Kardjarrimili Ngurranga. We Nyangumarta in the country of the Karajarri. Excerpts from field notes in northern Nyangumarta, as told to and translated by Father McKelson, and assisted by Tommy Dodd, 1968-9. Wangka Maya Pilbara Aboriginal Language Centre, Port Hedland, Australia.

Dowsley, M. 2009. Community clusters in wildlife and environmental management: using TEK and community involvement to improve co-management in an era of rapid environmental change. Polar Research 28(1):43-59.

Folke, C. 2004. Traditional knowledge in socialecological systems. Ecology and Society 9(3): 7. [online] URL: http://www.ecologyandsociety.org/vol9/ iss3/art7/. 
Folke, C., J. Colding, and F. Berkes. 2003. Synthesis: building resilience and adaptive capacity in social-ecological systems. Pages 352-387 in F. Berkes, J. Colding, and C. Folke, editors. Navigating social-ecological systems: building resilience for complexity and change. Cambridge University Press, Cambridge, UK.

Foreign Affairs and Trade. 1997. Seasons of the Kunwinjku: Aboriginal art from West Arnhem land. Foreign Affairs and Trade, Canberra, Australia.

Gadgil, M., F. Berkes, and C. Folke. 1993. Indigenous knowledge for biodiversity conservation. Ambio 22:151-156.

Gorman, J. T., A. D. Griffiths, and P. J. Whitehead. 2006. An analysis of the use of plant products for commerce in remote Aboriginal communities of northern Australia. Economic Botany 60(4):362-373.

Glowczewski, B., and Virtuel Bazaar. 2000. Dream trackers: Yapa art and knowledge of the Australian desert. CD-ROM. Warnayaka Art Centre and UNESCO Publishing, Paris, France.

Green, D., J. Billy, and A. Tapim. 2010. Indigenous Australians' knowledge of weather and climate. Climatic Change 100(2):337-354.

Green, D., and G. Raygorodetsky. 2010. Indigenous knowledge of a changing climate. Climatic Change 100(2):239-242.

Green, N. 1988. Aboriginal affiliations with the sea in Western Australia. Pages 19-29 in F. Gray and L. P. Zann, editors. Traditional knowledge of the marine environment in northern Australia: proceedings of a workshop held in Townsville, Australia, 29 and 30 July 1985. Great Barrier Reef Marine Park Authority, Townsville, Australia.

Harrison, K. D. 2007. When languages die. the extinction of the world's languages and erosion of human knowledge. Oxford University Press, Oxford, UK.

Hennessy, K., B. Fitzharris, B. C. Bates, N. Harvey, S. M. Howden, L. Hughes, J. Salinger, and R. Warrick. 2007. Australia and New Zealand. Pages 507-540 in M. L. Parry, O. F. Canziani, J. P. Palutikof, P. J. van der Linden, and C. E. Hanson, editors. Climate change 2007: impacts, adaptation and vulnerability. Contribution of Working Group II to the Fourth Assessment Report of the Intergovernmental Panel on Climate Change. Cambridge University Press, Cambridge, UK.

Hill, R., and A. Baird. 2003. Kuku-Yalanji rainforest Aboriginal people and carbohydrate resource management in the wet tropics of Queensland, Australia. Human Ecology 31 (1):27-52.

Hill, R., A. Baird, D. Buchanan, C. Denman, P. Fischer, K. Gibson, J. Johnson, A. Kerry, G. Kulka, E. Madsen, A. Olbar, L. Olbar, J. Pierce, J. Schuan, E. Shipton, H. Shipton, J. Smith, R. Sykes, E. Walker, W. Walker, P. Wallace, B. Yerry, D. Yougie, D. Ball, E. Barney, R. Buchanan, R. Buchanan, H. Denman, R. Fischer, R. Gibson, L. Talbot, E. Tayley, N. Tayley, D. Walker, K. Walker, M. Wallace, and L. Yougie. 2004. Yalanji Warranga Kaban: Yalanji people of the rainforest fire management book. Little Ramsay Press, Cairns, Australia.

Holling, C. S., L. H. Gunderson, and D. Ludwig. 2002. In quest of a theory of adaptive change. Pages 3-24 in L. H. Gunderson and C. S. Holling, editors. Panarchy: understanding transformations in human and natural systems. Island Press, Washington, D.C., USA.

Hoogenraad, R., and G. J. Robertson. 1997. Seasonal calendars from central Australia. Pages 34-41 in E. K. Webb, editor. Windows on meteorology: Australian perspective. CSIRO Publishing, Melbourne, Australia.

Houde, N. 2007. The six faces of traditional ecological knowledge: challenges and opportunities for Canadian co-management arrangements. Ecology and Society 12(2): 34. [online] URL: http: //www.ecologyandsociety.org/vol12/iss2/art34.

Humphries, P. 2007. Historical Indigenous use of aquatic resources in Australia's Murray-Darling Basin, and its implications for river management. Ecological Management and Restoration 8 (2):106-113.

International Union for Conservation of Nature. 2006. The future of sustainability: re-thinking environment and development in the twenty-first century. Report of the IUCN Renowned Thinkers Meeting, 29-31 January 2006. IUCN, Gland, 
Switzerland. [online] URL: http://cmsdata.iucn.org/ downloads/iucn future of sustanability.pdf.

Jackson, S., and P. O'Leary. 2006. Indigenous interests in tropical rivers: research and management issues. A scoping study for Land and Water Australia's Tropical Rivers Program. CSIRO Sustainable Ecosystems, Darwin, Australia. [online] URL: http://www.savanna.org.au/nailsma/ downloads/ Indigenous\%20interests\%20in\%20tropical\% 20rivers Research\%20and\%20Management.pdf.

Kneebone, E. 1993. Interpreting traditional culture as land management. Pages 227-235 in J. Birckhead, T. De Lacy, and L. Smith, editors. Aboriginal involvement in parks and protected areas: papers presented to a conference oranised by the Johnstone Centre of Parks, Recreation and Heritage at Charles Sturt University, Albury, New South Wales 22-24 July 1991. Aboriginal Studies Press, Canberra, Australia.

Lantz, T. C., and N. J. Turner. 2003. Traditional phenological knowledge of Aboriginal peoples in British Columbia. Journal of Ethnobiology 23 (2):263-286.

Latz, P. 1995. Bushfires and bushtucker: Aboriginal plant use in central Australia. IAD Press, Alice Springs, Australia.

Lawrence, A. 2009. The first cuckoo in winter: phenology, recording, credibility and meaning in Britain. Global Environmental Change 19 (2):173-179.

Lewis, H. T. 1989. Ecological and technological knowledge of fire: Aborigines versus park rangers in northern Australia. American Anthropologist 91 (4):940-961.

Lucas, D., M. Gapindi, and J. Russell-Smith. 1997. Cultural perspectives of the South Alligator River floodplain: continuity and change. Pages 120-135 in D. Bird Rose and A. Clarke, editors. Tracking knowledge in north Australian landscapes: studies in indigenous and settler ecological knowledge systems. Australian National University, Canberra, Australia.

Moore, B. 2007. The Wetj Boya (Wedge Island) Aboriginal sites: an action plan. Technical report. Yued Natural Resource Management Advisory
Group, Western Australia, Australia. [online] URL: http://www.noongar.org.au/images/pdf/misc/wedge. pdf.

Morton, S. R., D. M. Stafford Smith, C. R. Dickman, D. L. Dunkerley, M. H. Friedel, R. R. J. McAllister, J. R. W. Reid, D. A. Roshier, M. A. Smith, F. J. Walsh, G. M. Wardle, I. W. Watson, and M. Westoby. 2011. A fresh framework for the ecology of arid Australia. Journal of Arid Environments 75 (4):313-329.

Munn, N. D. 1992. The cultural anthropology of time: a critical essay. Annual Review of Anthropology 21:93-123.

Myers, F. R. 1986. Pintupi country, Pintupi self: sentiment, place, and politics among Western Desert Aborigines. Smithsonian Institution Press and Australian Institute of Aboriginal Studies, Washington, D.C., USA, and Canberra, Australia.

Natural Resources, Environment, the Arts, and Sport. No date. Section 3: Jawoyn culture. Pages 31-54 in Nitmiluk National Park tour guide handbook. Northern Territory Government, Darwin, Australia. [online] URL: http://www.nt.gov. au/nreta/parks/tour/guide/nnpguide.html or http://w ww.nt.gov.au/nreta/parks/tour/guide/pdf/nitmiluk/ nnps3 culture.pdf.

Newsome, A. E. 1980. The eco-mythology of the Red Kangaroo in central Australia. Mankind 12:327-333.

Nicholls, C. 2006. Yilpinji: love, art and ceremony. Craftsman House, Fishermans Bend, Australia.

Norris, R., and C. Norris. 2009. Emu dreaming: an introduction to Australian Aboriginal astronomy. Emu Dreaming, Sydney, Australia.

O'Connor, M. H., and S. M. Prober. 2010. A calendar of Ngadju seasonal knowledge. A report to the Ngadju Community and Working Group. CSIRO Ecosystem Sciences, Perth, Australia. [online] URL: http://www.csiro.au/resources/NgadjuCalendar.html.

O'Connor, R. 1997. The Kombumerri: Aboriginal people of the Gold Coast: ngulli yahnbai gulli bahn bugal bugalehn: we are still here. Self published, Brisbane, Australia. 
Orlove, B. S., J. C. H. Chiang, and M. A. Cane. 2000. Forecasting Andean rainfall and crop yield from the influence of El Niño on Pleiades visibility. Nature 403:68-71.

Parmesan, C. 2006. Ecological and evolutionary responses to recent climate change. Annual Review of Ecology, Evolution, and Systematics 37:637-669.

Parry, M. L., O. F. Canziani, J. P. Palutikof, P. J. van der Linden, and C. E. Hanson. 2007. Crosschapter case study. Pages 843-868 in M. L. Parry, O. F. Canziani, J. P. Palutikof, P. J. van der Linden, and C. E. Hanson, editors. Climate Change 2007: impacts, adaptation and vulnerability. Working Group II contribution to the Fourth Assessment Report of the Intergovernmental Panel on Climate Change. Cambridge University Press, Cambridge, UK.

Russell-Smith, J., D. Lucas, M. Gapindi, B. Gunbunuka, N. Kapirigi, G. Namingum, K. Lucas, P. Giuliani, and G. Chaloupka. 1997. Aboriginal resource utilization and fire management practice in Western Arnhem Land, monsoonal northern Australia: notes for prehistory, lessons for the future. Human Ecology 25(2):159-195.

Salick, J., and N. Ross. 2009. Traditional peoples and climate change. Global Environmental Change 19(2):137-139.

Sayer, J. A., and B. M. Campbell. 2004. The science of sustainable development: local livelihoods and the global environment. Cambridge University Press, Cambridge, UK.

Simpson, J. 1997. Perceptions of meteorology in some Aboriginal languages. Pages 20-28 in E. K. Webb, editor. Windows on meteorology: Australian perspective. CSIRO Publishing, Melbourne, Australia.

Smyth, D. 2007. Sea countries of the north-west: literature review on Indigenous connection to and uses of the North West Marine Region. Technical report. Department of the Environment, Water, Heritage, and the Arts, Canberra, Australia. [online] URL: http://www.environment.gov.au/coasts/mbp/ publications/north-west/pubs/nw-sea-countries.pdf
Turner, N. J., and H. Clifton. 2009. "It's so different today": Climate change and indigenous lifeways in British Columbia, Canada. Global Environmental Change 19(2):180-190.

Usher, P. J. 2000. Traditional ecological knowledge in environmental assessment and management. Arctic 53(2):183-193.

Walker, B., C. S. Holling, S. R. Carpenter, and A. Kinzig. 2004. Resilience, adaptability and transformability in social-ecological systems. Ecology and Society 9(2): 5. [online] URL: http://w ww.ecologyandsociety.org/vol9/iss2/art5/.

Walsh, F. J. 1990. An ecological study of traditional Aboriginal use of "country": Martu in the Great and Little Sandy Deserts, Western Australia. Pages 23-37 in D. A. Saunders, A. J. M. Hopkins, and R. A. How, editors. Australian ecosystems: 200 years of utilization, degradation and reconstruction: proceedings of a symposium held in Geraldton, Western Australia, 28 August-2 September, 1988. Surrey Beatty, Chipping Norton, Australia.

Walsh, F. J. 2008. To hunt and to hold: Martu Aboriginal people's uses and knowledge of their country, with implications for co-management in Karlamilyi (Rudall River) National Park and the Great Sandy Desert, Western Australia. Dissertation. University of Western Australia, Perth, Australia.

Walsh, F., B. Cross, and members of Wangkatjungka Aboriginal Corporation, Kupartiya Incorporated, Ngumpan Aboriginal Corporation, and Dodnun community. 2004. Bushfires and burning: aspects of Aboriginal knowledge and practice in areas of the Kimberley. Pages 27-69 in Sustainable fire management for the Kimberley region of Western Australia. Report from Kimberley Regional Fire Management Project to Natural Heritage Trust. Natural Heritage Trust project number 013005. Broome, Australia.

Walsh, F. J., and J. Douglas. 2009. Harvester-trader exchanges: critical elements of small-scale commercial bush produce harvesting in central Australia sustained to at least 2006. Pages 20-49 in M. Ryder, F. Walsh, J. Douglas, M. Waycott, H. Robson, Z. Singh, M. Majer, T. Collins, J. White, and B. Cheers, editors. Sustainable bush produce systems. Desert Knowledge CRC Working Paper 31. Desert Knowledge CRC, Alice Springs, 
Australia. [online] URL: http://www.desertknowled gecrc.com.au/publications/workingpapers.html.

Walsh, F., and P. Mitchell, editors. 2002. Planning for country: cross-cultural approaches to decisionmaking on Aboriginal lands. Jukurrpa Books, Alice Springs, Australia.

Wightman, G. 2003. Plants and animals of Kija and Jaru country: Aboriginal knowledge conservation and enthnobiological research in the upper Ord catchment, Western Australia. Land and Water Australia, Canberra, Australia. [online] URL: http: //lwa.gov.au/files/products/social-and-institutionalresearch-program/pn30249/plants-and-animals-kijaand-jaru-country.pdf.

Woodward, E., editor. 2009. Ngan'gi seasons calendar. Nauiyu-Daly River. TRaCK and CSIRO, Darwin, Australia. [online] URL: http://www.track. gov.au/publications/registry/429 or http://www.trac k.gov.au/sites/track.boab.info/files/uploads/ CSIRO Nauiyu calendar web.pdf.

Yu, S. 2000. Ngapa Kunangkal (living water): an indigenous view of groundwater: report on the Aboriginal cultural values of groundwater in the La Grange sub-basin. Technical report. University of Western Australia and Water and Rivers Commission, Crawley, Australia. 